\title{
Physicochemical Characteristics of Slag Rich Cement Pastes Incorporated by-pass Cement Dust
}

\author{
Kh. A. Khalil" and N. M. Abd-El- Hameed \\ Chemistry Department, Faculty of Science, Zagazig University, \\ Egypt.
}

\begin{abstract}
7 HE EFFECT of replacing ordinary Portland cement (OPC) and granulated blast furnace slag (GBFS) with by- pass cement dust (CKD) at $0 \%, 2.5 \%, 5 \%$, and 10 mass \% after 3, 7, 28 and 90 days of curing period was studded. One blend of slag rich cement was prepared, namely30/70 mass \% Portland cement and granulated slag, respectively. Two different mixes were made from this blend the first contains (70\% GBFS) with variable amounts of OPC and CKD, the second contains (30\% OPC)with variable amounts of GBFS and CKD. The hydration behavior was followed by estimation of combined water, bulk density and gel/space ratio. The required water for standard consistency, setting times and compressive strength were also determined. The required water for standard consistency increases with CKD content .The compressive strength and bulk density decrease with cement kiln dust. Combined water content increases with CKD. Initial sitting time for blended cement pastes with $(30 \%$ OPC) is elongated up to 5 mass \% then accelerated .The final sitting time of cement pasts ( $30 \% \mathrm{OPC}$ ) (is elongated with CKD . The results obtained were confirmed by XRD.
\end{abstract}

Keywords: Cement kiln dust, Compressive Strength, Slag and Portland cement.

Cement kiln dust (CKD), a by-pass dust, is generated in large the production of Portland cement. Cement kiln dust is a fine powdery material similar in appearance to Portland cement. It is composed of micron-sized particles collected in the control devices (e.g. cyclone, bag house, or electrostatic precipitator) during the production of cement clinker. The concentration of free lime, sulfates and alkalis in CKD mainly dependent upon the size of particles collected near to the kiln. Coarser particles of CKD contain high content of free lime while the fine particles usually exhibit higher concentration of sulfates and alkalis and lower lime content ${ }^{(1)}$. Several researchers have reported on some aspects of the utilization of CKD in cement paste, mortar/concrete ${ }^{(2-7)}$. The effect of cement kiln dust (CKD) on the compressive strength of cement paste and corrosion behavior of embedded reinforcement was investigated ${ }^{(2,8)}$.

*Corresponding author $+20552363728,01110808356$

E-mail address:khalilali9@gmail.com 
If CKD is used by replacing cement with $0 \% 5 \%, 10 \%, 15 \%, 20 \%, 25 \%$ and $30 \%$ CKD with water-to-binder ratio $0.50,0.60$, and 0.70 , respectively at the age of 3, 7 and 28 days, the increase in CKD replacement for cement decreased the compressive strength of concrete mixtures ${ }^{(4)}$.

The setting effect of replacing PC with CKD at $0 \%, 5 \%$ and $10 \%$ by mass in paste was studied $^{(2)}$ If CKD replacement with PC increases, the water demand increases and the setting time decreases.For these studies authors suggested that this was due to the high amounts of lime and alkalis in CKD .The utilization of CKD and some other industrial solid wastes in the field of cement industry and other building products was also reported ${ }^{(9,10)}$.

Portland cement clinker,BFS and CKD composites were investigated .Three blends of slag cement were prepared. Each blend was mixed with $2.5 \%, 5.0 \%$, $7.5 \%$, and $10.0 \% \mathrm{CKD}$. The authors reported that the substitution of 2.5 mass $\%$ CKD for mix (30 mass\% OPC +70 mass $\%$ GBFS) accelerates the final setting time $^{(11)}$.

The use of CKD as an activator for BFS was investigated. Binary blends containing slag and CKD from different sources were characterized and compared in terms of the rates of heat evolution and strength development, hydration products, and time of initial setting. It was reported that the combination of both chemical and physical characteristics of CKD is critical in controlling the mechanisms of activation of strength development ${ }^{(6)}$.

Investigation of the effect of CKD substitution on the mechanical properties of concrete was studied. Materials used in that research were "untreated" raw CKD which was collected from electrostatic precipitators, OPC, BFS, and sulfate resisting Portland cement (SRPC). It was reported that with increasing quantity of CKD, generally, the ultimate compressive as well as tensile strengths decreased for OPC concrete specimens; a slight increase in strength was observed for BFSC and SRPC. Further, it was found that the high limit for substitution was not more than $30 \%$ for SRPC, and $20 \%$ for BFSC, and $10 \%$ for $\mathrm{OPC}^{(12)}$.

Granulated blast-furnace slag by itself is hydraulically very weak. Due to its glassy structure, a highly alkaline medium is required in order to disintegrate the silicate-aluminates network of the slag glass; the liberated free lime during the hydration of Portland cement clinker is normally used to provide this alkalinity $^{(13)}$.

The aim of the present work is to study the effect of replacing of OPC and GBFS with CKD at $0 \%, 2.5 \%, 5 \%$ and $10 \%$ by mass in slag rich cement ( 30 mass $\%$ OPC +70 mass $\%$ GBFS). This was done via determination of compressive strength, chemically combined water, gel/ space ratio and bulk density, free lime contents at different ages of hydration. The phase composition was examined using XRD.

Egypt. J. Chem. 59, No. 4 (2016) 


\section{Experimental}

\section{Materials}

The materials used in this investigation were granulated blast furnace slag (GBFS ،(ordinary Portland cement) OPC (and cement kiln dust (CKD). GBFS was provided from Iron Steel Company, Helwan, Egypt .Ordinary Portland cement) OPC) and by pass cement dust) CKD) were supplied from Suez Cement Company .The results of chemical analysis of GBFS, OPC and CKD are given in Table 1.

TABLE 1. Chemical analysis of OPC, GBFS and CKD (mass\%).

\begin{tabular}{|c|c|c|c|c|c|c|c|c|c|c|}
\hline $\begin{array}{c}\text { Oxide } \\
\text { Materials }\end{array}$ & $\mathbf{S i O}_{2}$ & $\mathrm{Al}_{2} \mathbf{O}_{3}$ & $\mathbf{F e}_{2} \mathbf{O}_{3}$ & $\mathbf{C a O}$ & $\mathbf{M g O}$ & $\mathbf{S O}_{3}$ & $\mathbf{K}_{2} \mathbf{O}$ & $\mathbf{N a O}$ & $\mathbf{L . O . I}$ & $\begin{array}{c}\text { Surface } \\
\text { area(cm2/g) }\end{array}$ \\
\hline OPC & 19.8 & 4.70 & 3.14 & 62.0 & 2.13 & 3.1 & 0.1 & 0.20 & 3.70 & 3210 \\
\hline GBFS & 43.21 & 9.97 & 0.59 & 35.96 & 5.43 & 1.37 & 0.67 & 0.79 & 1.98 & 4500 \\
\hline CKD & 13.37 & 3.36 & 2.29 & 42.9 & 1.90 & 5.10 & 3.32 & 3.32 & 15.96 & 3500 \\
\hline
\end{tabular}

The mineralogical composition of CKD is shown in Fig.1. The XRD contained $\mathrm{CaCO}_{3}$ as a major phase with $\mathrm{NaKCl}_{2}$, quartz, and anhydrite.

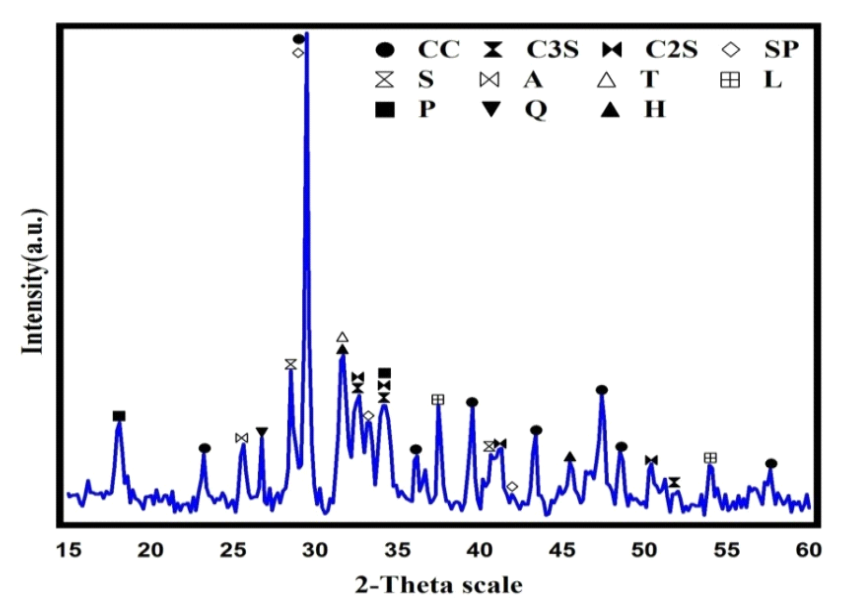

Fig. 1. XRD pattern of raw CKD. 


\section{Experimental techniques}

Preparation of cement pastes

Mixes were prepared by substitution of OPC with CKD and GBFS. The dry constituents of each mix were firstly blended for one hour in a porcelain ball mill using five balls to attain complete homogeneity, then kept in air tight container for further investigation.

The mixing of OPC with CKD and GBFS composite cement pastes was carried out with the water of consistency ASTM Designation: C191, $2008^{(14)}$. Freshly prepared pastes were placed in $2 \times 2 \times 2 \mathrm{~cm}$ cubic molds into two equal layers. The molds were then manually vibrated for few minutes then the pastes were smoothed by spatula. The specimens were cured with their molds at $100 \%$ R.H at $23 \pm 2^{\circ} \mathrm{C}$ for $24 \mathrm{hr}$. The cubic specimens were removed from their molds and then cured under tap water at room temperature for different time intervals of 3, 7, 28 and 90 days. The mix compositions of the prepared blends are shown in Table 2.

TABLE 2. Mix compositions of the prepared blended slag rich cements, mass \%.

\begin{tabular}{|c|r|c|c|}
\hline Sample & OPC & GBFS & CKD \\
A1 & 30 & 70 & 00 \\
\hline $\mathbf{A 2}$ & 27.5 & 70 & 2.5 \\
$\mathbf{A 3}$ & 25.5 & 70 & 5.0 \\
\hline $\mathbf{A 4}$ & 20.0 & 70 & 10.0 \\
\hline
\end{tabular}

\begin{tabular}{|c|c|c|c|}
\hline Sample & OPC & GGBFS & CKD \\
\hline A1 & 30.0 & 70 & 00 \\
\hline B1 & 30.0 & 67.5 & 2.5 \\
\hline B2 & 30.0 & 65.0 & 5.0 \\
\hline B3 & 30.0 & 60.0 & 10.0 \\
\hline
\end{tabular}

The initial and final setting times were determined according to ASTM Designation: C-191, $2008^{(14)}$. The bulk density of cement pastes was measured before the specimens subjected to compressive strength determination. Each measurement was carried out on at least three similar cubes of the same mix composition and curing time ${ }^{(15)}$.

Compressive strength was determined according to ASTM Designation: C$150,2007^{(17)}$. A set of three cubes was tested using compressive strength machine of SEIDNER, Riedinger, Germany, with maximum capacity of 2000 $\mathrm{KN}$ force. The resulting crushed specimens of the hardened cement pastes were ground and the hydration reaction was stopped ${ }^{(17)}$. The samples were then dried at $80^{\circ} \mathrm{C}$ for $3 \mathrm{hr}$ in $\mathrm{CO}_{2}$ - free atmosphere.

The chemically combined water content, $(\mathrm{Wn}, \%)$, was determined by the ignition loss test at $1000^{\circ} \mathrm{C}$ for $1 \mathrm{hr}$. Duplicate measurements were carried out for each sample and the mean value was recorded ${ }^{(18)}$. The free lime content, $\mathrm{CaO}$ (\%), was determined by using the glycerol/ ethanol extraction method and the mean value of the two independent determinations was recorded ${ }^{(19)}$.The gel/ space ratio $(x)$ was calculated from the degree of hydration and water to cement ratio ${ }^{(20,21)}$.

Egypt. J. Chem. 59, No. 4 (2016) 
for some selected hydrated samples using X-ray diffraction analysis (XRD). XRD analysis was performed using cobalt target $(\chi=0.17889) \mathrm{nm})$, and nickel filter under working conditions of $40 \mathrm{kv}$ and $40 \mathrm{~mA}$.

\section{Results and Discussion}

\section{Substitution of OPC by CKD in granulated slag rich cement}

Water of consistency and setting times

The water of consistency and setting time for slag rich cement containing 70 mass\% of GBFS and variable amounts of OPC and CKD are plotted as a function of CKD content in Fig. 2. The water of consistency of blended slag rich cement pastes is higher than that for cement pastes without CKD. Addition of CKD increases the water for normal consistency. This may be attributed to the high amounts of alkali, sulfates, and volatile salts as well as the higher surface area of CKD that require more water ${ }^{(7,11)}$.

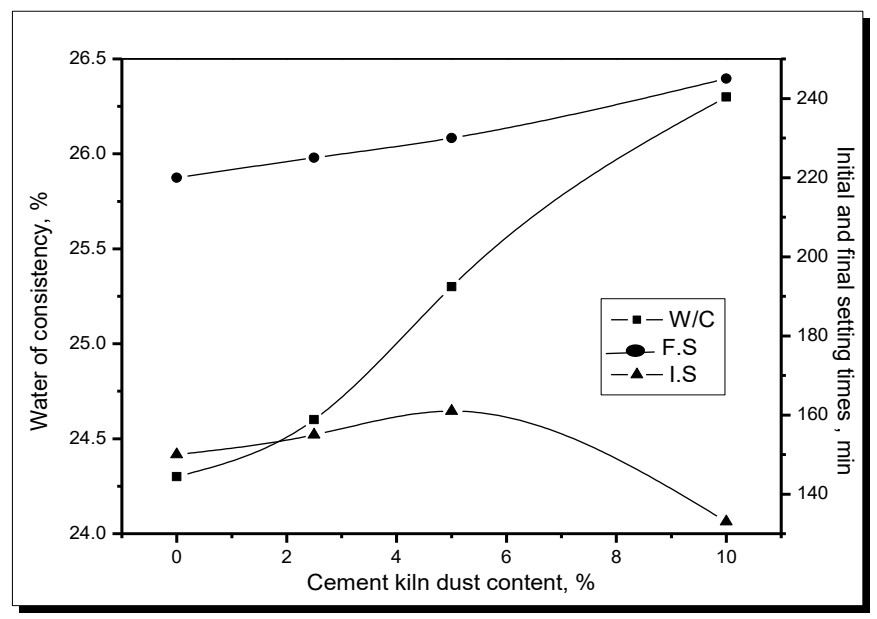

Fig. 2. Water of standard consistency, initial and final setting times of cement pastes with variable amounts of OPC and CKD.

The initial setting time is elongated up to 5 mass $\%$ CKD and then shortened up to 10 mass \%. The elongation of initial setting time at low content of cement dust may be due to the dilution of OPC portion in addition to the increase of water of consistency. The decrease of initial setting time of cement pastes containing 10.0 mass \% CKD is mainly due to the excess amount of alkalis and lime which can accelerate the hydration of granulated slag cement paste ${ }^{(7,11)}$. On the other hand, the final setting time of cement pastes is elongated with CKD content due to the decrease of the formed C-S-H which is the main cementing 
phase. Therefore, as the amount of CKD increases the final setting of hardened cement pastes elongates ${ }^{(11)}$.

Chemically combined water contents and gel/space ratio

The results of chemically combined water content for all pastes investigated, OPC-GBFS, and OPC-GBFS-CKD are given in Fig. 3. As shown from the figure the combined water contents increase gradually with curing time up to 90 days for all cement pastes. This is due to the progress of hydration. As the hydration proceeds, the amount of hydration products increase and the combined water also increases. As the CKD increases the combined water content increases gradually up to $2.5 \%$. This is due to that, the CKD contains some alkalis, chlorides and sulfates with hydrated lime which act as activator for GBFS. As the cement kiln dust increases up to $5 \%$ and $10 \%$, the combined water content decreases than that of control sample (30\% OPC +70 GBFS). This is mainly due to the decrease of the amount of OPC with the increasing of cement dust. Accordingly, the OPC phases such as $\mathrm{C}_{3} \mathrm{~S}, \beta \mathrm{C}_{2} \mathrm{~S}, \mathrm{C}_{3} \mathrm{~A}$ and $\mathrm{C}_{4} \mathrm{AF}$ are diminished. These phases with their hydraulic characteristics certainly influence the chemically combined water.

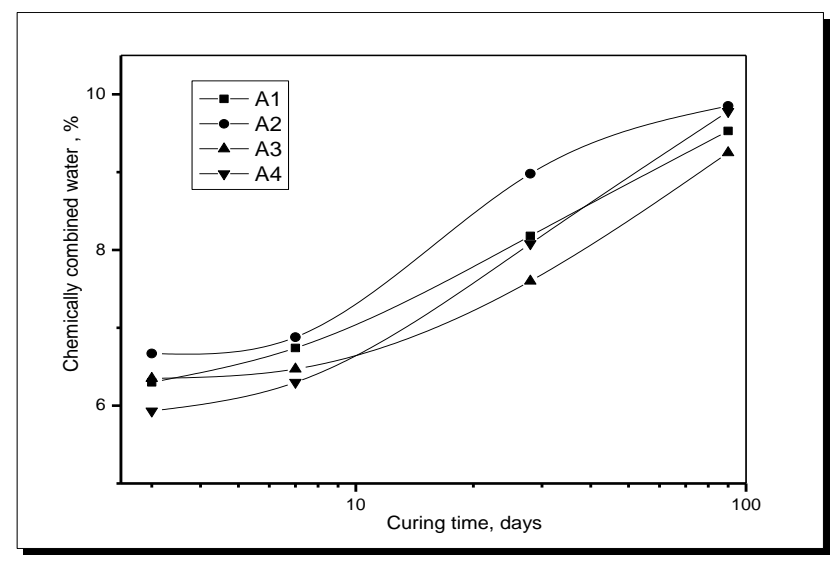

Fig. 3. Combined water contents of cement paste with variable amount of OPC and CKD up to 90 days.

On the other hand, the cement kiln dust has no hydraulic characteristics, it consists mainly of $\mathrm{CaCO}_{3}$ with some alkaline and quartz ${ }^{(7,16)}$.

The gel space ratio of cement pastes was calculated from the data of the degree of cement hydration, which obtained from combined water in relation to that of complete hydration ${ }^{(20,21)}$. The higher the degree of hydration, the higher the gel content of the paste. 
The results of gel / space ratio of cement pastes containing GBFS with variable amount of OPC and CKD are given in Fig. 4.

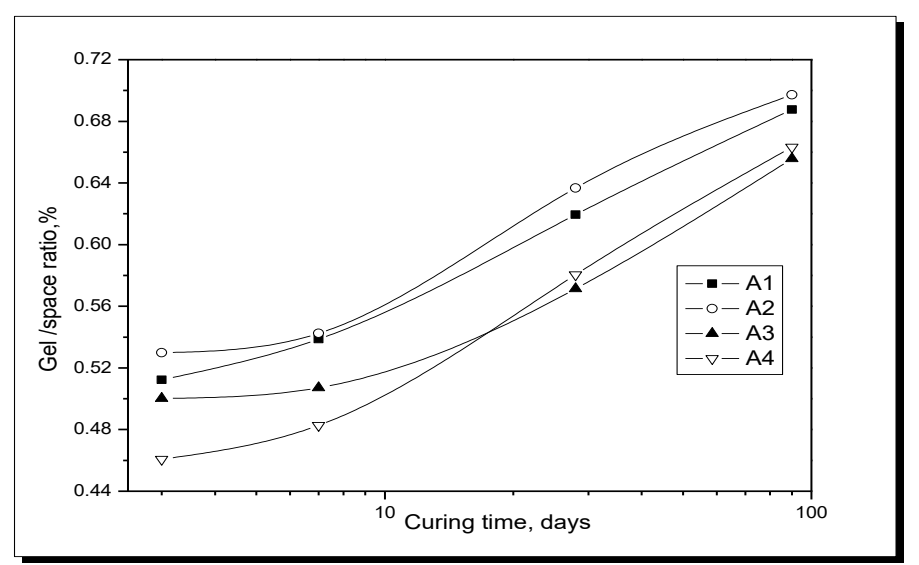

Fig. 4. Gel/ space ratio of cement paste with variable amount of OPC and CKD up to 90 days .

The results indicate that gel / space ratio increases with curing time for all hydrated cement pastes. This is due to the continuous hydration of cement phases, leading to the formation and accumulation of excessive amounts of more dense hydrated products ( $\mathrm{CSH}, \mathrm{CAH}$, and $\mathrm{CASH})^{(18)}$. The formations of these hydrated products improve the microstructures of cement pastes. Gel / space ratio of blended cement pastes decreases with the CKD up to 10 mass \%. This is mainly attributed to the decrease of combined water and may be partially due to the lower density of pozzolanic hydration products, and it may indicate that pozzolanic reaction products are more effective in filling pores ${ }^{(22)}$.

\section{Compressive strength and bulk density}

The results of compressive strength and bulk density of hardened composite GBFS cement pastes containing CKD as a partial replacement of OPC increase with curing time for all hydrated cement pastes as demonstrated in Fig. 5. and 6.

This is mainly due to the increase of the hydration products and their accumulation such as $\mathrm{C}-\mathrm{S}-\mathrm{H}$ (the main source of strength) within the available spaces giving a compact matrix with higher strength ${ }^{(23)}$. 


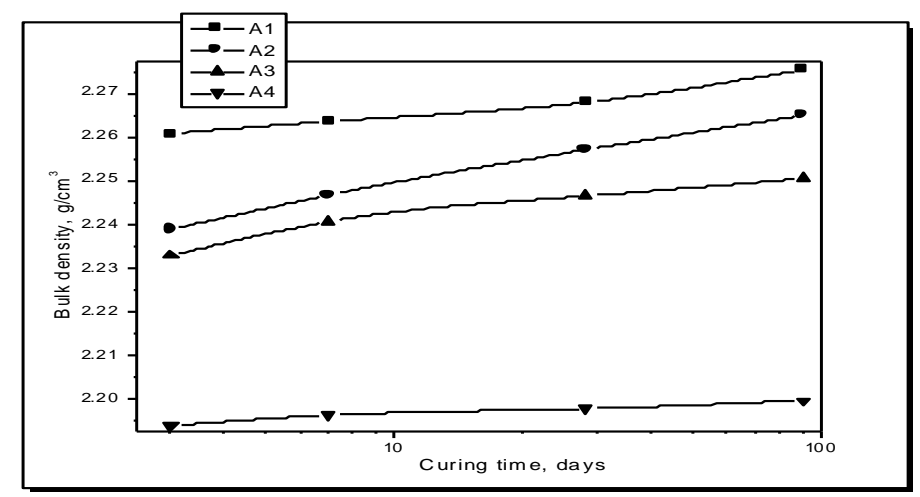

Fig. 5. Bulk density of cement paste with variable amount of OPC and CKD up to 90 days.

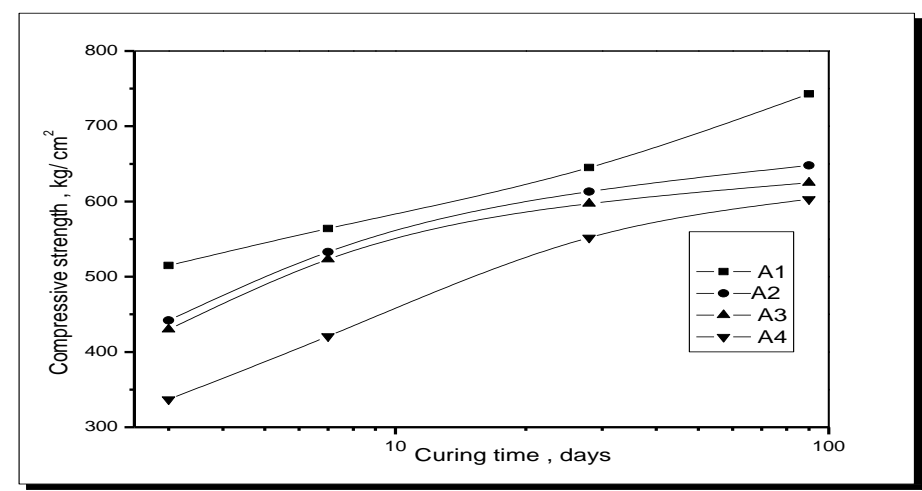

Fig. 6. Compressive strength of cement paste with variable amounts of OPC and CKD up to 90 days.

The compressive strength and bulk density of composite GBFS cement pastes decrease with CKD as a partial replacement of OPC. This is mainly due to the increase of $\mathrm{W} / \mathrm{b}$ ratio and the formation of sulphoaluminate, chloroaluminate as well as carboaluminate hydrates with low strength and bulk density in addition to the decrease of C-S-H binding centers in the cement pastes. Control cement A1 (30\% OPC $+70 \%$ GBFS) without CKD, shows the highest compressive strength and bulk density in comparison with those containing CKD. This is mainly due to that, high content of OPC which is the more reactive component. This reduction in compressive strength is proportional to the CKD content, which affects the mechanical properties of the hardened cement pastes. These results are in good agreement with those of combined water and bulk density values ${ }^{(4)}$. The hydration products of pozzolanic cement pastes have lower density than that of only GBFS pastes without $\mathrm{CKD}^{(24)}$. This may be due to the presence of anhydrite, $\mathrm{CaCO}_{3}, \mathrm{KCl}$ 
and chlorides in the $\mathrm{CKD}$, which gives $\mathrm{AFt}$, AFm, chloroaluminate and carboaluminate hydrates with expansion and then low bulk density ${ }^{(4)}$.

\section{XRD analysis}

Figure 7 Illustrates the XRD- patterns of composite cement pastes containing $30 \%$ OPC with variable amounts of GBFS and CKD hydrated for 90 days. The diffraction patterns show the diffraction lines of hydrated and unhydrated cement phases namely, $\quad \beta-\mathrm{C}_{2} \mathrm{~S}, \mathrm{C}_{3} \mathrm{~S}$, calcium hydroxide $(\mathrm{CH})$, calcite $(\mathrm{CC}),(\mathrm{C}-\mathrm{S}-\mathrm{H})$ overlapped by $\mathrm{CC}$ and wallastonite. It is clear that the peaks of portlandite decrease with GBFS and CKD content due to the dilution of OPC which liberates portlandite in addition, to the pozzolanic reaction of active silica and alumina of GBFS with portlandite. The peaks of $\beta-\mathrm{C}_{2} \mathrm{~S}$ and $\mathrm{C}_{3} \mathrm{~S}$ are still present. The decrease of CC peaks in $\mathrm{A} 1$ and $\mathrm{A} 2$ may be also due to its reaction with $\mathrm{CO}_{2}$ in the presence of moisture forming $\mathrm{Ca}\left(\mathrm{HCO}_{3}\right)_{2}{ }^{(24)}$ as follows:

$$
\mathrm{CaCO}_{3}+\mathrm{CO}_{2}+\mathrm{H}_{2} \mathrm{O} \longrightarrow \mathrm{Ca}\left(\mathrm{HCO}_{3}\right)_{2}
$$

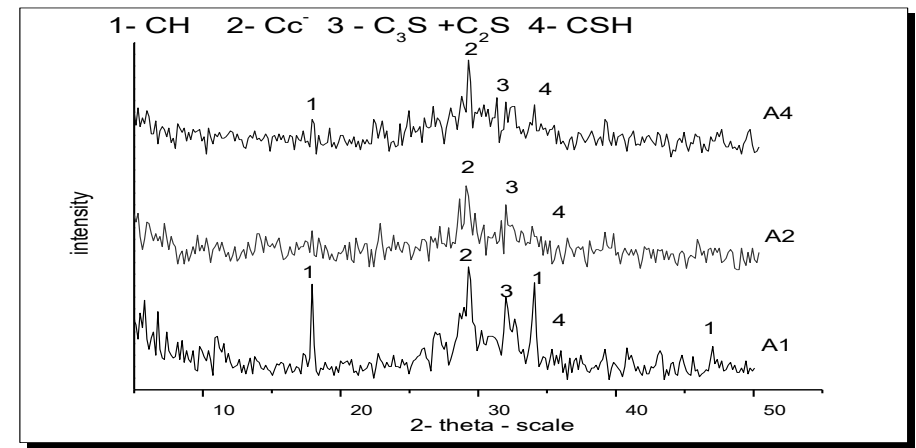

Fig. 7. XRD patterns of A1, A2 and A4 up to 90 days.

Substitution of GBFS by CKD in granulated slag rich cement

Water of standard consistency and setting times

The variations of the required water for consistency, initial and final setting times of composite slag rich cement pastes containing variable amounts of GBFS and CKD are given in Fig. 8. The water of standard consistency of slag rich cement pastes increases with the increase of content of CKD, this is due to the presence of a high amount of lime, sulfates, alkalis and chlorides in CKD, as well as the high surface area leading to high water demand ${ }^{(1,7)}$.

The initial setting time (IST) of cement pastes is shortened with the CKD wt $\%$. This is mainly due to the presence of some alkalis and sulfates in addition to $\mathrm{CaCO}_{3}$, which accelerate the initial setting. Also, the decrease of GBFS in the blended cement with low hydration characteristics in comparison with the OPC shortens the initial setting time ${ }^{(7)}$. 
It is clear that, FST of cement pastes is elongated linearly with substitution of GBFS with CKD. This may be due to that, CKD delays the formation of hydration products especially $\mathrm{C}-\mathrm{S}-\mathrm{H}$ gel ( the main binding hydration product) and forms some gehlenite hydrate $\left(\mathrm{C}_{2} \mathrm{ASH}_{8}\right)$ sulphoaluminate, carboaluminate and chloro-aluminate hydrates which delay the final setting time due to the coating effect of these hydrates on the anhydrous cement grains ${ }^{(11)}$.

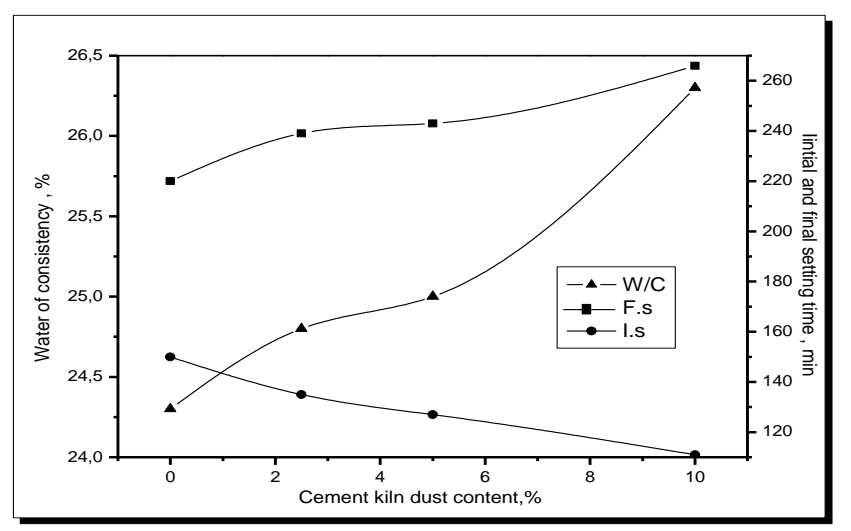

Fig. 8. Water of standard consistency, initial and final setting times of cement pastes with variable amounts of GBFS and CKD.

Chemically combined water and gel/ space ratio

Figure 9 and 10 show the variations of the chemically combined water contents and gel/ space ratio of slag rich cement pastes hydrated up to 90 days, containing $30 \%$ OPC as well as variable amounts of GBFS and CKD. The results show that, $\mathrm{Wn} \%$ and gel/ space ratio\% increase with the increase of curing time for all hydrated cement pastes. This is due to the progress of hydration and the increasing of the hydration products. The values of $\mathrm{Wn}$ and gel/ space ratio increases with increase of CKD; this is due to CKD has high lime, alkalis and sulfate contents which make it an excellent activator for pozzolanic materials ${ }^{(6)}$. On the other hand, the cement pastes without CKD give lower Wn content than those containing CKD. This indicates also that, the CKD acts as an activator for the hydration of GBFS due to its contamination of lime, alkalis and sulfate. The gel/space ratio of cement pastes was calculated based on the data of degree of hydration, obtained from Wn content. This leads to increase of the amount of hydration products, which fill the pores between the cement particles. Therefore, the porosity decreases and the gel space ratio increases $(17,21)$.

Egypt. J. Chem. 59, No. 4 (2016) 


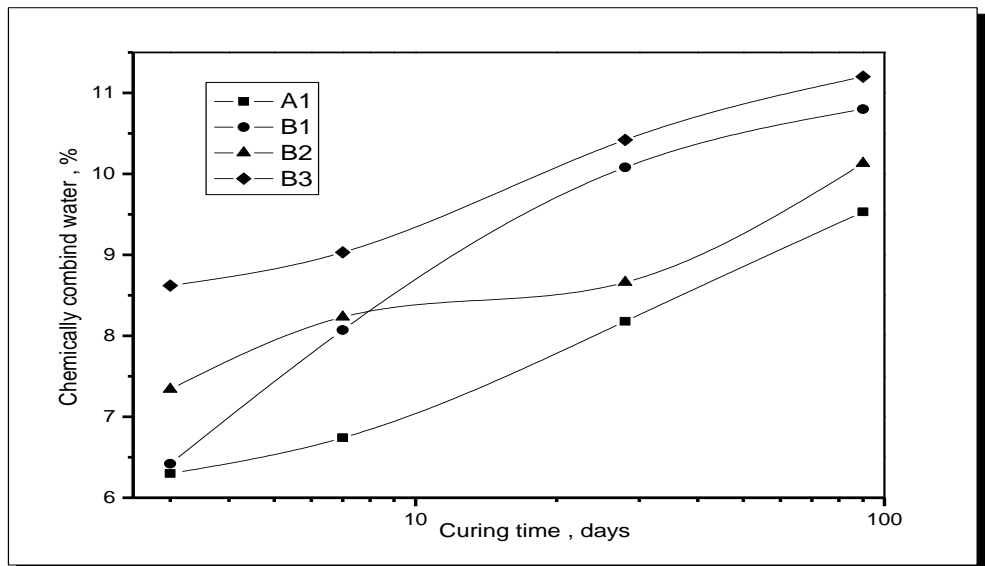

Fig. 9. Combined water contents of cement paste with variable amount of OPC and CKD up to 90 days.

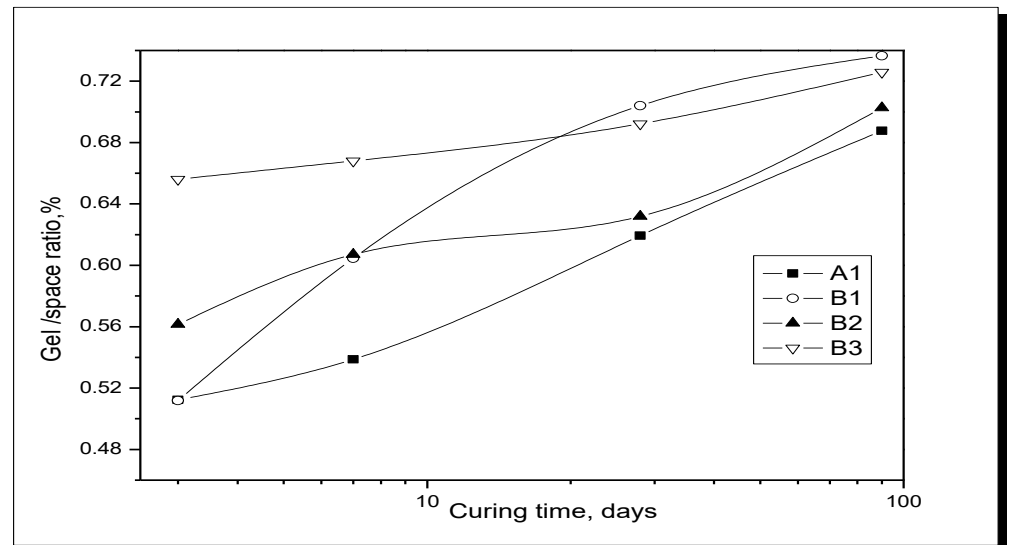

Fig. 10 . Gel/ space ratio of cement paste with variable amounts of GBFS and CKD up to 90 days.

\section{Compressive strength and bulk density}

The compressive strength and bulk density of slag rich cement pastes containing 30\% OPC and variable amounts of GBFS and CKD are given in Fig. 11 and 12. The compressive strength and bulk density of all composite cement pastes increase with curing time. This is due to the continuous hydration of OPC as well as pozzolanic reaction of GBFS, which activated by the liberated $\mathrm{CH}$ during the hydration of OPC and CKD. This leads to the increase of the precipitated hydration products, that fill some of the open pores of cement paste, 
which increases the bulk density ${ }^{(5,7)}$. Shi ${ }^{(25)}$ concluded that the increases strength of the blends with time was due to the availability of $\mathrm{Ca}^{+2}$ ions provided by the free lime content.

As the amount of CKD increases, the compressive strength and bulk density of composite cement pastes decreases ${ }^{(23)}$. The hydration of slag rich cement pastes gives $\mathrm{CSH}$ with low $\mathrm{C} / \mathrm{S}$ which tends to decrease the bulk density ${ }^{(6)}$. AS the CKD content increases up to 10 mass $\%$, the compressive strength and bulk density decrease significantly. The decrease of compressive strength and bulk density with CKD can be attributed to the increase of w/b ratio as well as the increase in free lime content in cement dust; the higher amount of $\mathrm{Ca}(\mathrm{OH})_{2}$ weakened the hardened matrix. Also, the formation of chloro - and sulfoaluminate phases leads to the softening and expansion of the hydration products. The formation of these hydration products enhances the crystallization. This may be accompanied by an increase in the pore size due to a change in the packing between the crystal, this leads to decline in the strength ${ }^{(7,11,12)}$.

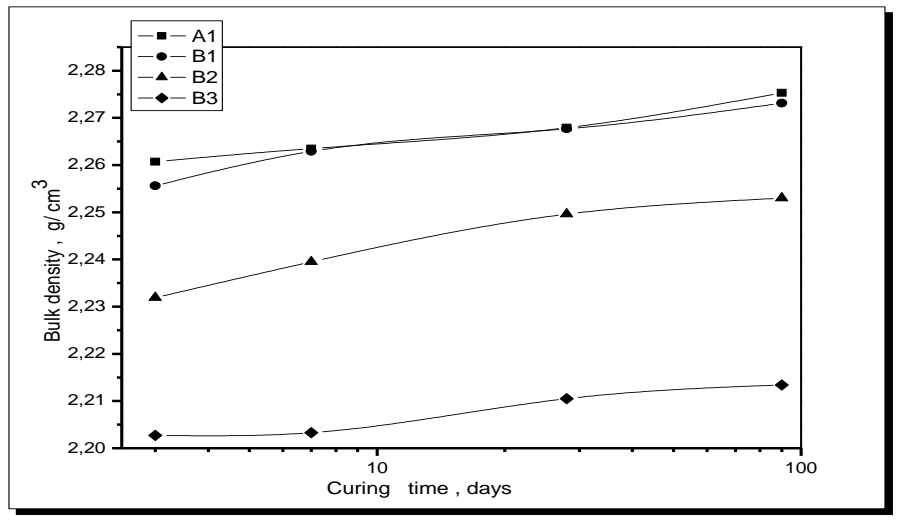

Fig. 11. Bulk density of hydrated cement paste with variable amounts GBFS and CKD up to 90 days. 


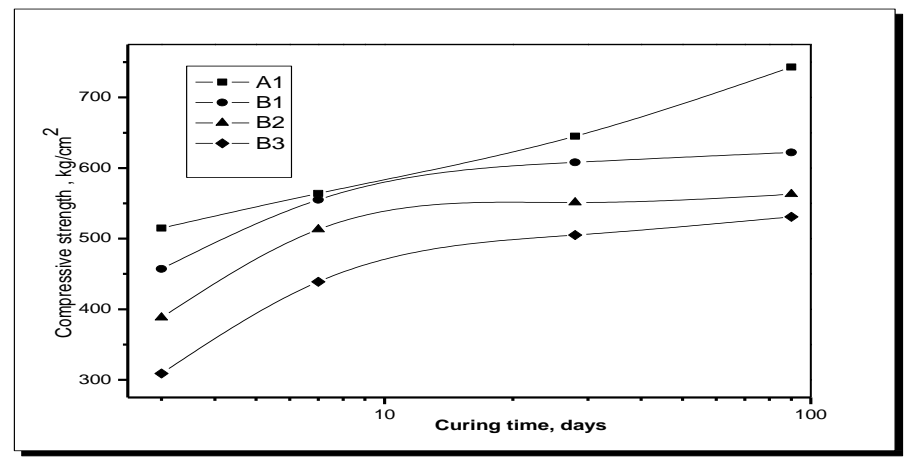

Fig. 12. Compressive strength of cement paste with variable amounts of GBFS and CKD up to 90 days.

Free lime contents

The results of free lime contents of slag rich cement containing 30\% OPC and variable amounts of GBFS and CKD are given in Fig. 13. The results indicate that the values of free lime increase up to 7 days, then decrease with curing time up to 90 days for mixes with $0 \%$ and 10 mass \%CKD. This is mainly due to that, the rate of liberation of portlandite exceeds its rate of consumption by GBFS at early ages. Therefore, the liberated $\mathrm{Ca}(\mathrm{OH})_{2}$ is lower than that for cement pastes without CKD . The decrease of free lime at 5.0 and $10.0 \mathrm{wt} \%$ CKD may be due to that, the CKD acts as activator. The decrease of free lime after 7 days can be attributed to the pozzolanic activity of slag increase at latter ages, which consume more portlandite. The increase of GBFS decreases the free lime content. Cement pastes containing 10.0 mass \% CKD give higher values of free lime than that, with 5.0 mass $\%$ CKD, due to the decrease of GBFS as pozzolanic material in addition to $\mathrm{Ca}^{2+}$ leached from $\operatorname{CKD}^{(7,11)}$.

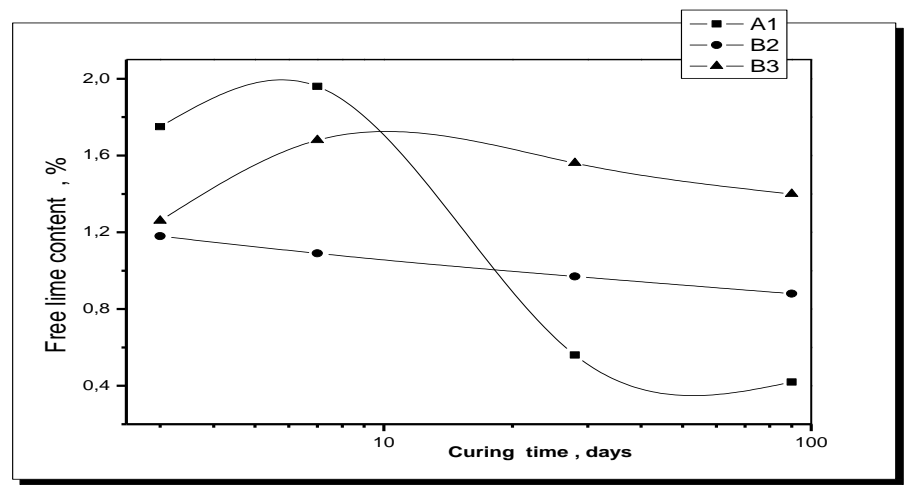

Fig. 13. Free lime content of cement paste with variable amounts of GBFS and CKD up to 90 days. 


\section{Conclusions}

The following conclusions may be drawn from the obtained experimental data.

[1] The substitution of CKD to slag rich cement $(30 \%$ OPC $+70 \%$ GBFS) decreases the compressive strength and bulk density.

[2] The combined water content and gel space ratio for the blended cements incorporated with CKD is more than that without CKD.

[3] The substitution of slag rich cement with CKD increases the water of consistency.

[4] The high alkali and sulfate content in CKD makes it an excellent activator for pozzolanic materials.

[5] Free lime content of slag rich cement contains $30 \%$ OPC and 70\% GBFS increases up to 7 days, then decreases with curing time up to 90 days.

[6] Slag rich cement pastes without CKD give high values of free lime than that containing CKD at early ages.

\section{References}

1. Kunal, Rafat Siddique and Anita Rajor; A review on the use of cement kiln dust in cement concrete and its leachate characteristics. Res. Con. and Recy, 6159-68(2012).

2. Maslehuddin, M., Al-Amoudi O.S.B., Rehman M.K., Ali M.R. and Barry M.S. Properties of cement kiln dust concrete. Constr Build Mater 23, 2357-61(2009).

3. Al-Jabri, K.S., Taha, R.A., Al-Hashmi, A. and Al-Harthy, A.S., Effect of copper slag and cement by-pass dust addition on mechanical properties of concrete. Constr Build Mater.. 20,322-31(2006).

4. Al-Harthy, A.S., Taha, R. and Al-Maamary, F., Effect of cement kiln dust (CKD) on mortar and concrete mixtures. Constr Build Mater. 17, 353-60 (2003).

5. Amin, A.M., Ebied, E. and El-Didamony, H., Activation of granulated slag with calcined cement kiln dust. Silic Ind .60, 109-15 (1995).

6. Konsta-Gdoutos, M.S. and Shah, S.P., Hydration and properties of novel blended cements based on cement kiln dust and blast furnace slag. Cem. Concr. Res. 33,1269$76(2003)$.

7. El-Aleem,S.A., Abd-El-Aziz, M.A., Heikal, M. and El-Didamony, H., Effect of cement kiln dust substitution on chemical and physical properties and compressive strength of Portland and slag cements. Arab. J. Sci. Eng. 30, 263-73(2005).

8. El-Sayed, H.A., Gabr, N.A., Hanafi, S. and Mohran, M.A., Reutilization of bypass kiln dust in cement manufacture. In: Proceedings of the international conference on blended cement in construction (1991).

Egypt. J. Chem. 59, No. 4 (2016) 
9. Abo-El-Enein, S.A. Utilization of cement kiln dust in cement industry and building products. First International Symposium on the Cement Industry, Assiut, Egypt, pp. 8-10(1997).

10. Abo-El-Enein, S.A., Utilization of industrial solid wastes in the field of building materials technology .Proc. 1st .Ain Shams Univ . Inter .Confr .Environ. Eng., Cairo. pp. 1125-1141(2005).

11. Heikal, M. ، Aiad, I. and Helmy ,M.I., Portland cement clinker, granulated slag and y-pass cement dust composites. Cem. Concr. Res. 32,1805-12(2002).

12. Shoaib, M.M., Balaha, M.M. and Abdel-Rahman, A.G., Influence of cement kiln dust substitution on the mechanical properties of concrete. J. Cem. Concr. Res. 30, 371-377(2000).

13. Wanga, Xiao-Yong, Leea Han-Seung, Parkb Ki-Bong, Kimc Jae-Jun and Goldend, Jay S., A multi-phase kinetic model to simulate hydration of slag-cement blends. J. Cem. Concr. Compos. 32, 468-477(2010).

14. ASTM Designation: C191, Standard method for normal consistency and setting of hydraulic cement, in: ASTM Annual Book of ASTM Standards,(2008).

15. Abd-El-Eziz, M.A. and Heikal, M., Hydration characteristics and durability of cements containing fly ash and limestone subjected to Qaron's Lake Water, Adv Cem Res. 21(3),91-9(2009).

16. ASTM C109. Strength test method for compressive strength of hydraulic cement mortars; (2007).

17. Abd-El-Aziz, M.A., Abd.El. Aleem, S. and Heikal, M., Physico-chemical and mechanical characteristics of pozzolanic cement pastes and mortars hydrated at different curing temperatures. Constr Build Mater 26,310-316(2012).

18. El-Didamony, H., Aiad, I., Heikal, M. and Al-Masry, S., Impact of delayed addition time of SNF condensate on the fire resistance and durability of SRC-SF composite cement pastes, Constr Build Mater. 50, 281-290(2014).

19. Heikal, M., Ali, A.I., Ismail, M.N., Awad, S. and Ibrahim, N.S., Behavior of composite cement pastes containing silica nano-particles at elevated temperature, Constr. Build. Mater. 70, 339-350 (2014).

20. Older , I. and RÖßler, M., Investigation on the relation ship between porosity structure and strength of hydrated Portland cement pastes, II. Effect of pore structure and degree of hydration, Cem Concr Res. 15, 401-410(1985).

21. Heikal, M. and Ibrahim, N.S., Hydration, microstructure and phase composition of composite cements containing nano-clay. Constr. Build. Mater 112,19-27(2016).

22. Feldman, R.F. and Huang Cheng-yi, Properties of portland cement-silica fume pastes II. Mechanical properties. Cem. Concr. Res. 15, .943- 952(1985). 
23. Khan, M.I., Lynsdale. C.I. and Waldron, P., 'Porosity and strength PFA/SF/OPC ternary blended pastes. Cem. Concr. Res. 30(8),1225-1229(2000).

24. Ramachandran , V.S., Paroh, R.M., Beadocin, J.J. and Delgado, A. H., Handbook of Thermal Analysis of Construction Materials , Newes Pupl., New York., U.S. A. (2002).

25. Shi, C., Studies on several factors affecting hydration and properties of lime pozzolana cements. J. Mater Civil Eng 13,441-5(2001). 


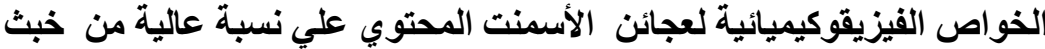

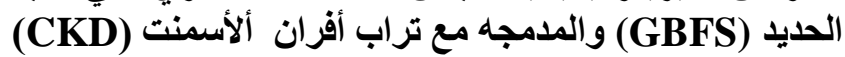

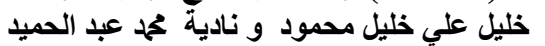

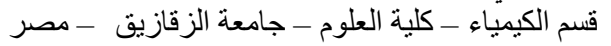

الهدف من هذا البحث هو دراسة الخو اص الفزيقوكيميائية للأسمنتات البوزو لانية المستخدم فيها تراب أفران

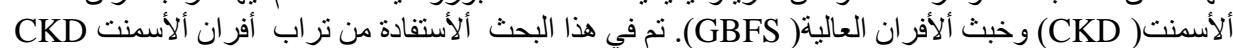

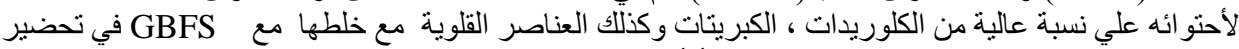

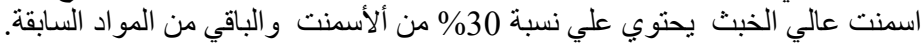

وقد تم في هذ البحث تعيين كمية الماء القباسية وزمني الثك ألأبتدائي و النهائي ودر اسة كيناتيكية

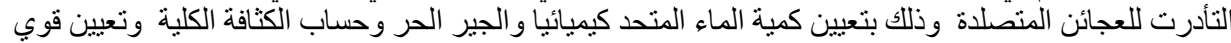
التحمل ونو اتج التأدرت باستخدام جهاذ XRD.

أظهرت النتائج ان كمبة الماء القياسية تزداد بزيادة نسبة CKD وتنسر ع من زمن الثكا ألأبتدائي ولكن

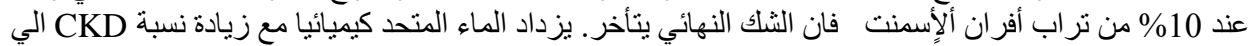

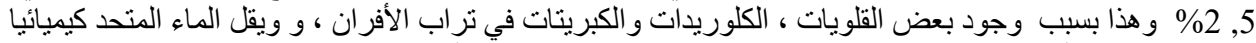

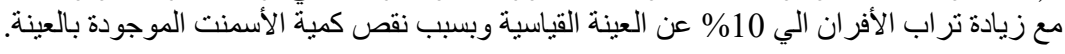

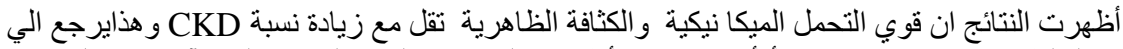

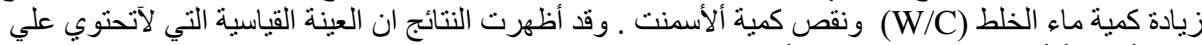

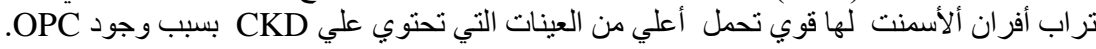

